\title{
Ionospheric Anomalies Observed by GPS TEC Prior to the Qinghai-Tibet Region Earthquakes
}

\author{
Chunliang $\mathrm{Xia}^{1,{ }^{*}}$, Shaomin Yang ${ }^{1,2}$, Guirong $\mathrm{Xu}^{3}$, Biqiang Zhao ${ }^{4}$, and Tao $\mathrm{Yu}^{5}$ \\ ${ }^{1}$ Institute of Geophysics and Geomatics, China University of Geosciences, Wuhan, China \\ ${ }^{2}$ Institute of Seismology, China Earthquake Administration, Wuhan, China \\ ${ }^{3}$ Institute of Heavy Rain, China Meteorological Administration, Wuhan, China \\ ${ }^{4}$ Beijing National Observatory of Space Environment, Institute of Geology and Geophysics, \\ Chinese Academy of Sciences, Beijing, China \\ ${ }^{5}$ National Center for Space Weather, China Meteorological Administration, Beijing, China
}

Received 31 January 2009, accepted 13 August 2010

\begin{abstract}
The precursory processes detected from unambiguous and repeatable instrumental observations that precede an earthquake remain elusive despite the multiple types of pre-earthquake signals gained from observations of geo-electricity, geomagnetism, and electromagnetism. Recently, much attention has been paid to associate abnormal behaviors of TEC (total electron content) in ionosphere, with seismic forcing. In this paper, we examined ionospheric TEC variations $1-2$ weeks preceding 20 moderate to great earthquakes $(M=5-8)$ in the Tibetan Plateau and its neighboring regions between 1999 to 2008, with the help of a nationwide continuously-tracking GPS network. The temporal and spatial TEC variations over the specific seismogenic zones were calculated, and the causal linkage between the identified TEC anomalies and these earthquakes was examined. We find that most of the earthquakes showed significant abnormalities with similar characteristics. The anomalies, either upper anomalies $(85 \%, 17 / 20)$ or lower anomalies $(65 \%, 13 / 20)$ occurred in the ionosphere with dimensions of $30^{\circ}$ in latitude and $30^{\circ}$ in longitude above the epicenters. It is noted that the ionospheric anomalies were more dependent on focal depths of earthquakes than their magnitudes. Our results suggest that these anomalies of TEC may be possible seismoionospheric signatures for the earthquakes in Tibet and its margins.
\end{abstract}

Key words: Earthquake, Ionosphere, GPS TEC, Anomaly

Citation: Xia, C., S. Yang, G. Xu, B. Zhao, and T. Yu, 2011: Ionospheric anomalies observed by GPS TEC prior to the Qinghai-Tibet region earthquakes. Terr. Atmos. Ocean. Sci., 22, 177-185, doi: 10.3319/TAO.2010.08.13.01(TibXS)

\section{INTRODUCTION}

When Leonard and Barnes (1965) first showed that some level of ionospheric disturbances had preceded strong earthquakes, many studies have demonstrated unambiguously that a large earthquake not only ruptured the surface of the Earth, but also disturbed the atmosphere and ionosphere (Leonard and Barnes 1965; Weaver et al. 1970; Hayakawa and Fujinawa 1994; Liu et al. 2000; Pulinets et al. 2000; Popov et al. 2004; Liperovskaya et al. 2006; Yu et al. 2009). Although a number of researchers have made considerable effort recently in understanding the causal linkage between seismic activities and ionospheric variabilities, the seismic

\footnotetext{
* Corresponding author

E-mail:xia.cl.cug@gmail.com
}

coupling of the lithosphere-atmosphere-ionosphere system is still less well known. So far the unambiguous precursor identified from complicated ionospheric signals prior to an earthquake is still debated because other factors such as geomagnetic activity may trigger a similar response in the ionosphere, forcing detectable TEC anomalies over a broad area, for example, large day-to-day variability in the ionosphere (Liu et al. 2008b).

To address the problem, statistical analyses of tens or hundreds of earthquakes in pre-seismic ionospheric behaviors on various spatial and temporal scales were ever used to explore the relationship of ionosphere perturbation to earthquakes (Liu et al. 2004; Pulinets and Boyarchuk 2004; Liu et al. 2009). In this paper, in order to gain a robust insight into the ionospheric precursor of an earthquake, we examined 
abnormal variations in the local ionosphere for earthquakes which occurred in the Qinghai-Tibet region from 1999 to 2008 , of which 20 major events were investigated. We classified these earthquakes in terms of their magnitudes, focal depths and corresponding ionospheric parameters (TEC), and tried to associate spatio-temporal variations in the TEC value with the earthquakes of interest. We found that the repeated anomalies preceded most of the earthquakes. We discussed the possibility that the ionospheric anomalies were used as the precursors of the earthquakes.

\section{METHODOLOGY AND TEC MEASUREMENTS}

Ionospheric total electron density can be derived from trans-ionospheric GPS signals recorded at ground-based GPS receivers by means of calculating the difference between the P1/P2 pseudoranges and the combination of the phases at two carrier signals (L1/L2) (Klobuchar 1991). The relevant equations are:

$\operatorname{STEC}_{L}=\left[\left(\frac{f_{2}^{2}}{f_{1}^{2}-f_{2}^{2}}\right) \frac{2 f_{1}^{2}}{K}\right]\left(P_{2}-P_{1}\right)$

$\operatorname{STEC}_{P}=\left[\left(\frac{f_{2}^{2}}{f_{1}^{2}-f_{2}^{2}}\right) \frac{2 f_{1}^{2}}{K}\right]\left(L_{1} \lambda_{1}-L_{2} \lambda_{2}\right)$ where $f_{1}$ and $f_{2}$ are GPS signal frequencies at 1.57542 and $1.2276 \mathrm{GHz}$, respectively, $\lambda_{1}$ and $\lambda_{2}$ are the corresponding wavelengths. $K=80.62 \mathrm{~m}^{3} \mathrm{~s}^{-2}$ is a constant that relates the plasma frequency to the electron density. The STEC can be expressed as:

$S T E C=S T E C_{P}+B_{c o r r}$

$B_{\text {corr }}=\sqrt{\sum_{i=1}^{N}\left(S T E C_{L}-S T E C_{P}\right)^{2} / N}$

where $N$ is the number of measurements sampled during a satellite pass.

Based on the thin-shell model for the Earth's ionosphere, the vertical TEC (VTEC) can be calculated by:

$V T E C=\left(S T E C-B^{S}-B_{R}\right)\left[\sqrt{1-\left(\frac{R_{e} \times \cos \varepsilon}{R_{e}+h_{s}}\right)^{2}}\right]$

where $B_{S}$ and $B_{R}$ are the instrumental biases related to GPS satellites and receivers respectively; $R_{e}=6371 \mathrm{~km}$ is the mean radius of the Earth; $\varepsilon$ is the elevation angle of a GPS satellite. In the following, we use the TEC in place of VTEC for convenience.

Figure 1a and Table 1 show the GPS-derived param- (a)

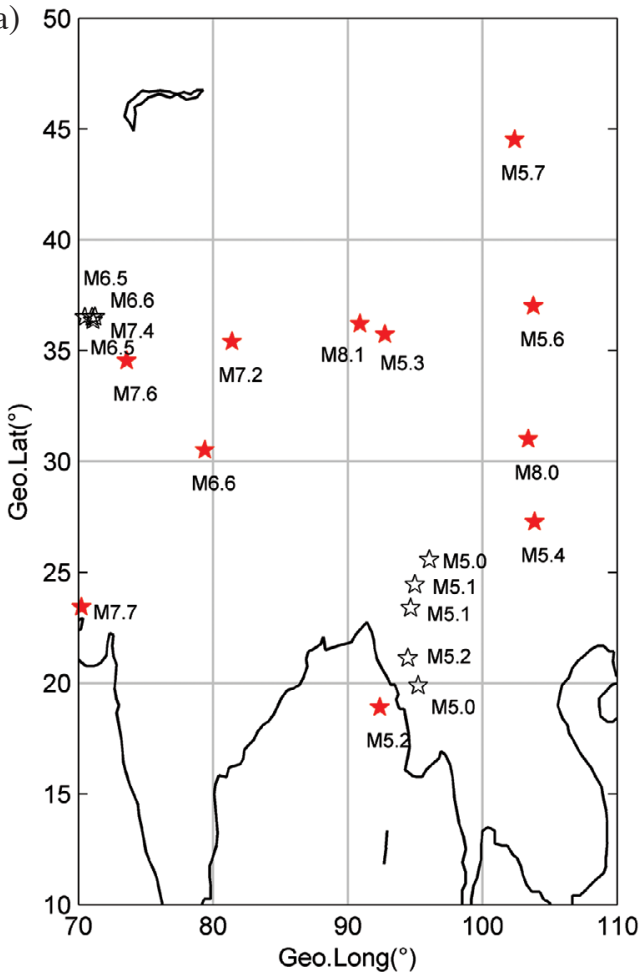

(b)

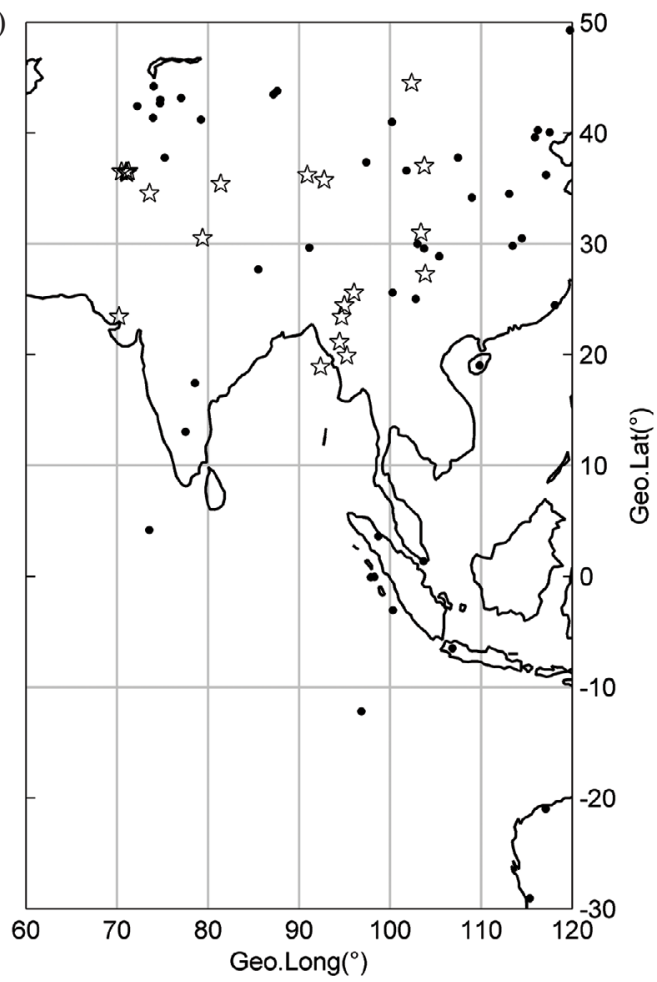

Fig. 1. (a) Locations of 20 earthquakes from 1999 to 2008 in the Qinghai-Tibet region. The red solid pentagrams show the epicenters of the earthquakes with focal depths $<40 \mathrm{~km}$ and the black hollow pentagrams for the earthquakes with the depths $>100 \mathrm{~km}$. (b) Locations of the GPS receivers (dots) and epicenters (pentagrams). 
eters for a total of 20 large to moderate earthquakes, most of which happened in the periods when the solar and geomagnetic activities were quiet. We classified these earthquakes by their magnitudes and focal depths. In terms of the magnitude, 10 events with a magnitude greater than 6.5 are referred as the large earthquakes, the remaining 10 are intermediate-sized events $(6.0>M>5.0)$. According to their focal depths, 11 earthquakes are the shallow events with depths less than $40 \mathrm{~km}$ (red solid pentagrams in Fig. 1a), the others are the deep earthquakes with epicenters exceeding $100 \mathrm{~km}$ in depth (black hollow pentagrams in Fig. 1a). To distinguish the spatial and temporal irregular behaviors of the ionosphere, we chose a network of 58 ground-based GPS stations in eastern Asia, including stations of the Crustal Movement Observation Network of China (CMONOC).
Figure $1 b$ shows the epicenters of these earthquakes (pentagrams) and distribution of GPS receivers (dots) from which data are available for us.

\section{TEC VARIATIONS AND PRESEISMIC ABNOR- MALIES}

To identify seismic signals from the GPS-derived TEC variation, we adopted Liu et al.'s method to estimate the vertical TEC of the ionosphere above the epicenters (Liu et al. 2006, 2009). We computed the median $\tilde{X}$ over an interval of 15-running-day, and the associated inter-quartile range between the lower quartile (LQ) and upper quartile (UQ) of GPS TEC estimates. Then we isolated the TEC anomalies by setting the upper bound $U B=\widetilde{X}+1.5(U Q-\tilde{X})$ and

Table 1. Parameters of the 20 seismic events.

\begin{tabular}{|c|c|c|c|c|c|c|}
\hline EQK (No.) & Date (YY/MM/DD) & Time (UT) & Geo.Lat. $\left({ }^{\circ} \mathbf{N}\right)$ & Geo.Long. $\left({ }^{\circ} \mathbf{E}\right)$ & Mag. & Depth (km) \\
\hline 1 & $1999 / 03 / 28$ & 19:05 & 30.51 & 79.40 & 6.6 & 15 \\
\hline 2 & 1999/11/08 & $16: 45$ & 36.52 & 71.24 & 6.5 & 228 \\
\hline 3 & 2000/06/06 & 10:59 & 37.01 & 103.79 & 5.6 & 10 \\
\hline 4 & $2001 / 01 / 26$ & 03:16 & 23.42 & 70.23 & 7.7 & 16 \\
\hline 5 & $2001 / 08 / 12$ & $01: 58$ & 24.43 & 94.99 & 5.1 & 121 \\
\hline 6 & $2001 / 10 / 13$ & $20: 54$ & 18.90 & 92.38 & 5.2 & 10 \\
\hline 7 & $2001 / 11 / 14$ & 10:00 & 36.2 & 90.9 & 8.1 & 15 \\
\hline 8 & 2001/12/08 & $04: 12$ & 35.73 & 92.77 & 5.3 & 10 \\
\hline 9 & $2002 / 03 / 03$ & $12: 08$ & 36.50 & 70.48 & 7.4 & 225 \\
\hline 10 & 2003/01/17 & $02: 53$ & 19.89 & 95.24 & 5.0 & 101 \\
\hline 11 & $2004 / 04 / 05$ & $21: 24$ & 36.51 & 71.03 & 6.6 & 187 \\
\hline 12 & $2004 / 08 / 10$ & $10: 26$ & 27.27 & 103.87 & 5.4 & 6 \\
\hline 13 & 2005/10/08 & 03:50 & 34.54 & 73.59 & 7.6 & 26 \\
\hline 14 & $2005 / 10 / 22$ & $13: 45$ & 25.57 & 96.05 & 5.0 & 102 \\
\hline 15 & $2005 / 12 / 12$ & $21: 47$ & 36.36 & 71.09 & 6.5 & 224 \\
\hline 16 & $2006 / 03 / 03$ & 01:36 & 21.12 & 94.47 & 5.2 & 112 \\
\hline 17 & $2006 / 04 / 30$ & $00: 43$ & 44.52 & 102.39 & 5.7 & 7 \\
\hline 18 & $2007 / 11 / 29$ & 19:00 & 23.39 & 94.68 & 5.1 & 114 \\
\hline 19 & $2008 / 03 / 20$ & $22: 33$ & 35.4 & 81.4 & 7.2 & 33 \\
\hline 20 & $2008 / 05 / 12$ & $06: 28$ & 31.0 & 103.4 & 8.0 & 14 \\
\hline
\end{tabular}


lower bound $L B=\tilde{X}+1.5(L Q-\tilde{X})$. According to the Liu et al.'s method, possible earthquakes related perturbations are detected if the observed TEC data fall out of either the lower or upper bound, and the confidence level for the seismic signals is about $80-85 \%$ (Liu et al. 2000, 2001, 2004).

With the GPS-derived TEC time series from 58 stations, we calculated the TEC variations over the epicenters within a time window encompassing earthquakes, and distinguished the marked abnormalities that might be related to the forthcoming earthquakes. The ionospheric variations can be found in VLF signals in 5 - 10 days period before the earthquakes (Molchanov and Hayakawa 1998; Chuo et al. 2002). We chose the TEC data associated with these earthquakes with the periods of 31 running days around the earthquakes ( 15 days before and 15 days after) with a time sampling rate of 15 minutes. The possible seismic signals were extracted according to the upper and lower bounds (UB/LB) described above. To avoid large day-to-day variability (Liu et al. 2008b; Zhao et al. 2008b) and reduce the disturbances caused by other geophysical phenomena such as geomagnetic storms, we examined only the anomalies that persisted for at least 3 hours in a local day. That is, the anomaly is qualified as the plausible seismic signal only if it was beyond the upper/lower bounds for $>3$ hours in a day (here termed upper/lower anomaly), and the geomagnetic environment was generally quiet on the day $(K p \leq 3$ and $A E<300 n T$ ). When one-third and more of a 24-hour-long TEC time series for a full day went beyond the upper or lower bound, the day was treated as an upper or lower abnormal day (Liu et al. 2009).

Figures $2 \mathrm{a}$ and $3 \mathrm{a}$ show the variations of upper/lower anomalies extracted from the TEC observations in 31 days around the targeted earthquakes, respectively. Only the qualified anomalies whose durations were more than 3 hours in a day beyond the bounds were displayed. The red curves in Figs. 2a and 3a denote the abnormal days in which TEC data exceeded the prescribed upper or lower limits (UB/LB) for a total of 8 hours or more in time. Figures $2 b$ and $3 b$ show the counts of the upper/lower anomalies (gray histograms) and abnormal days (dark histograms) for each day. In Figs. 2 and 3 the horizontal axis is the local day during the earthquakes. Figures 2 and 3 illustrate that the $85 \%$ (17 of

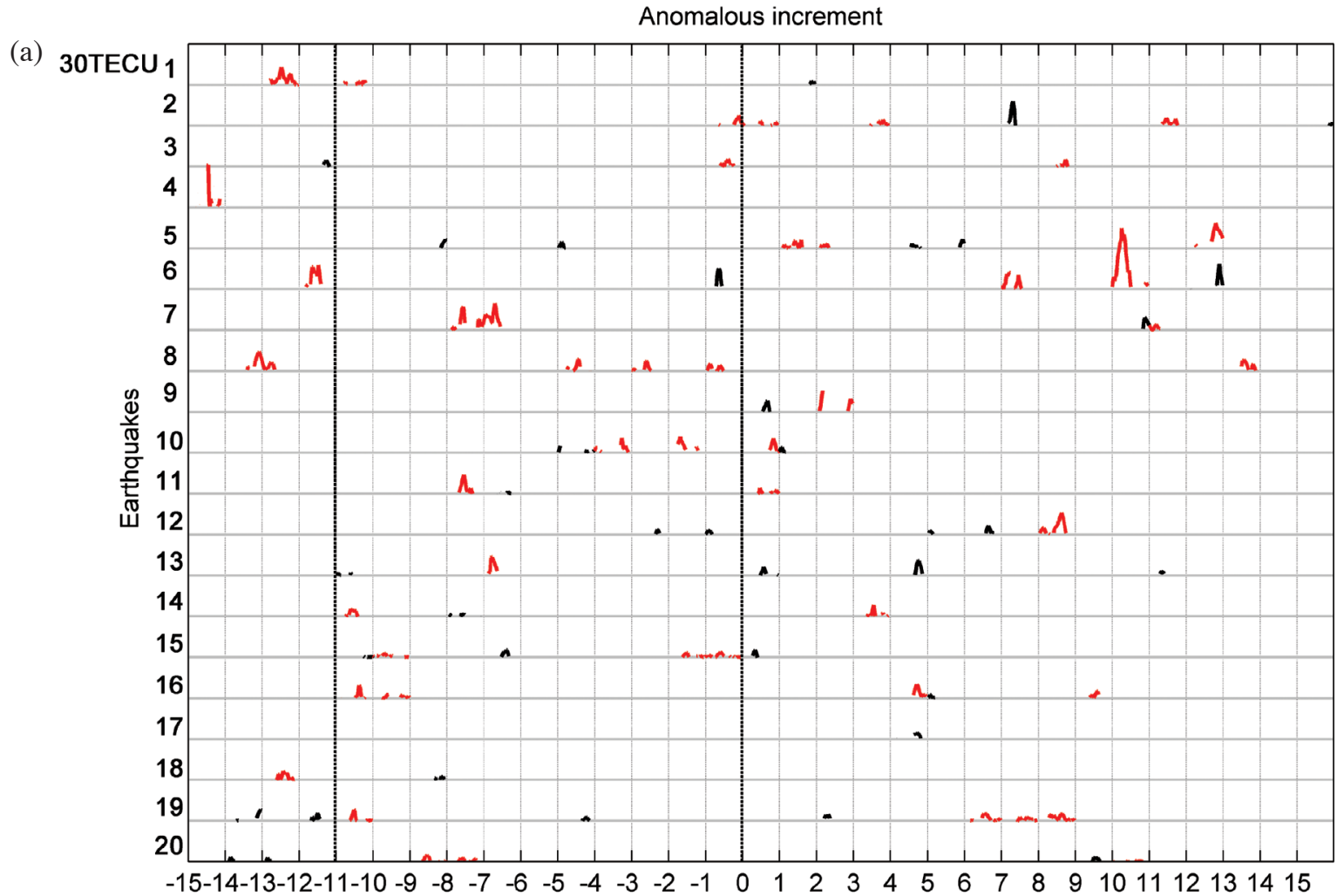

(b)

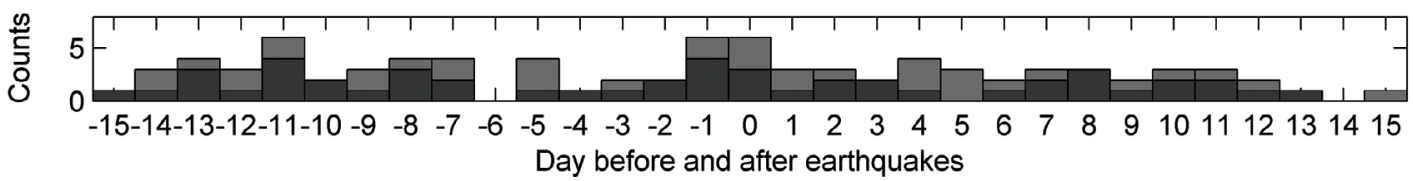

Fig. 2. The upper anomalies that occurred in 31 days surrounding the earthquakes. (a) The observed GPS TEC exceed the specific upper bound (UB). The red lines denote the abnormal days. (b) The counts of upper anomalies (gray histograms) and abnormal days (dark histograms) for each day. 
(a) 30TECU 1

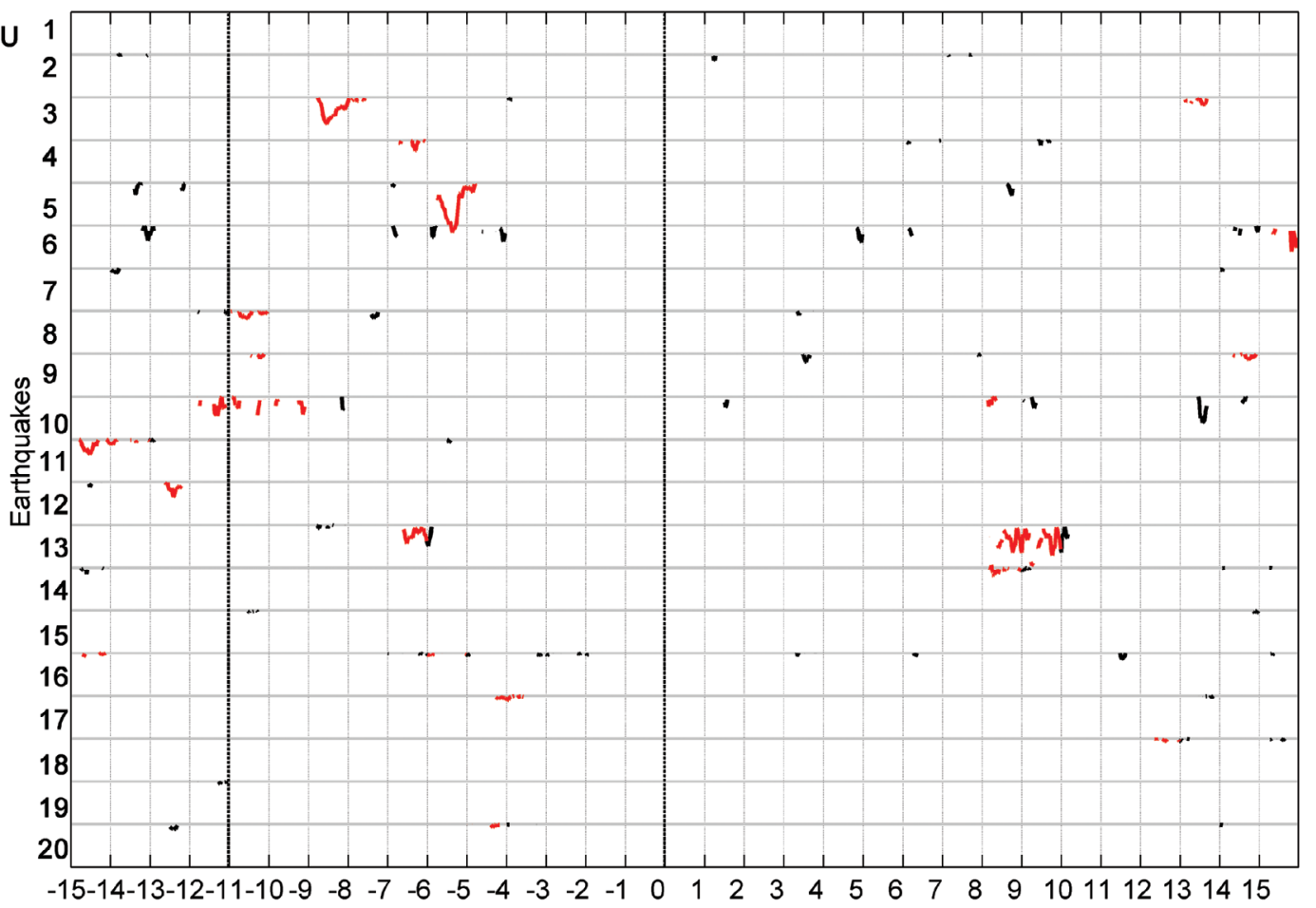

(b)

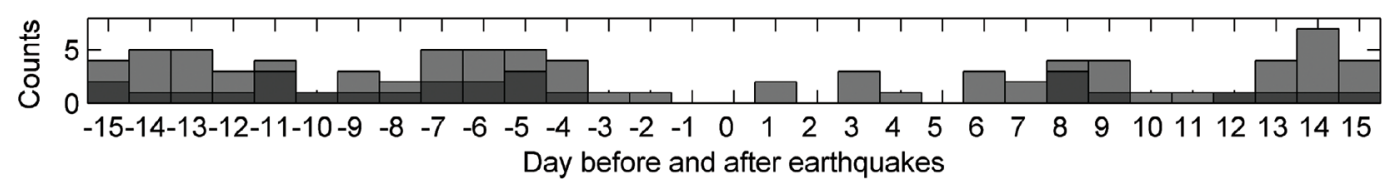

Fig. 3. The lower anomalies that occurred in the 31 days surrounding the earthquakes. (a) The observed GPS TEC exceed the associated lower bound (LB) in which the red lines denote the abnormal days. (b) The counts of lower anomalies (gray histograms) and abnormal days (dark histograms) for each local day.

20) of earthquakes appeared to exhibit the pre-earthquake upper anomalies and 65\% (13 of 20) appeared to have the lower anomalies in 11 days before the earthquakes. It is noted that upper anomalies mainly happened $1-3$ days and 8 - 11 days prior to the earthquakes. The 7 days ( 1 - 3 days and 8 - 11 days before earthquakes) average of the emergence frequency of the upper anomalies is $17.86 \%$ while the 31 -day average is about $13.87 \%$. And the lower anomalies mainly happened 4 - 7 days prior to the earthquakes. The 4 days (4 - 7 days before earthquakes) average of the emergence frequency of the lower anomalies is $23.75 \%$ while the 31 -day average is about $13.7 \%$. The statistics about more obvious anomalies, the abnormal days, are 65\% (13 of 20) of the upper anomalies and 50\% (10 of 20) of the lower anomalies in 11 days before the earthquakes. Figure 4 shows the daily counts of the upper and lower anomalies during 31 days around the earthquakes. It is noted that the focal depth will affect the occurrence of the upper/lower anomalies while different magnitudes have little effect on it.

We also studied spatial variations in TEC associated with earthquakes. Note that the radius $\mathrm{R}$ of the epicentral area can be given by the following equation (Dobrovolsky et al. 1979):

$R=10^{0.43 M}$

where $M$ is the earthquake magnitude. For an appreciation, the 2008 Wenchuan earthquake $\left(M_{\mathrm{s}} 8.0\right)$ in the eastern Tibet, the largest earthquake we investigated, had a radius of $2754 \mathrm{~km}$ for the possible seismo-electromagnetic areas. Taking the epicenters as the centers of regions with dimensions of $60^{\circ}$ in latitude and $60^{\circ}$ in longitude, we divided it into 30 by 30 grids of $2^{\circ}$ in latitude and $2^{\circ}$ in longitude respectively. We calculated the relative differential TEC (RTEC, subtract the 15-day mean value) in a 3-hour interval from 1 to 15 days before each event, then computed the average of the RTEC of these 20 earthquakes. Figure 5 shows the two-dimensional maps of the RTEC mean values during 0800 - 1100 UT respectively 3, 4, 5 and 8 days before the earthquakes. The red pluses denote the epicenters. It is interesting that with the time approaching the earthquakes, the RTEC variation first increased, then decreased, and in- 

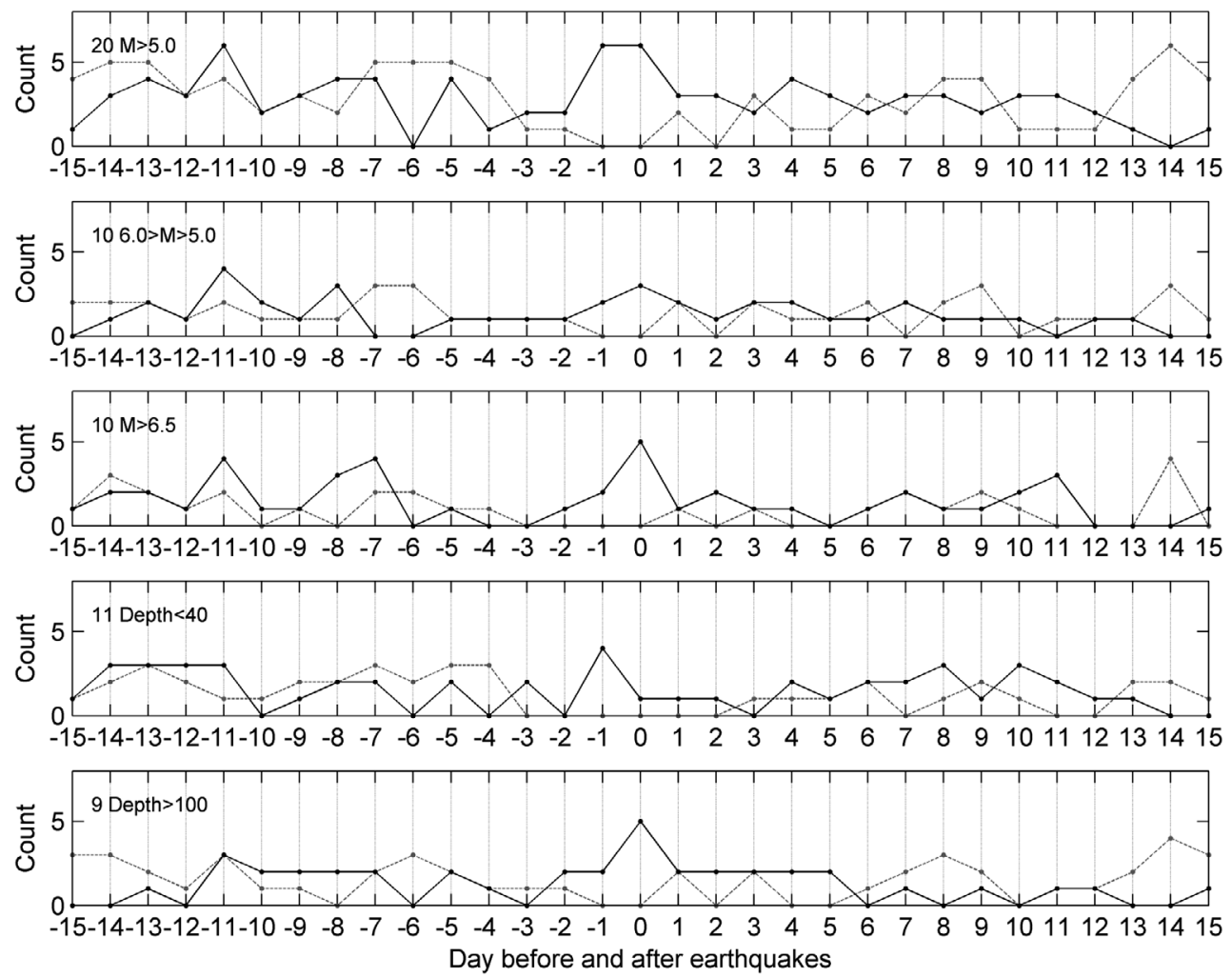

Fig. 4. The daily counts of the upper (solid black curves) and lower (dashed gray curves) anomalies during the 31 days surrounding the earthquakes. From top to bottom are the statistics during the $20 \mathrm{M}>5.0,106.0>\mathrm{M}>5.0,10 \mathrm{M}>6.5,11$ Depth $<40$ and 9 focal depth $>100 \mathrm{~km}$ earthquakes, respectively.

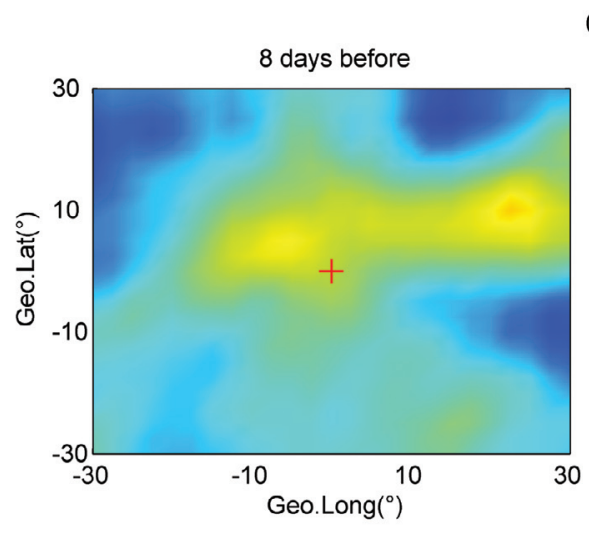

08:00 - 11:00 UT

5 days before
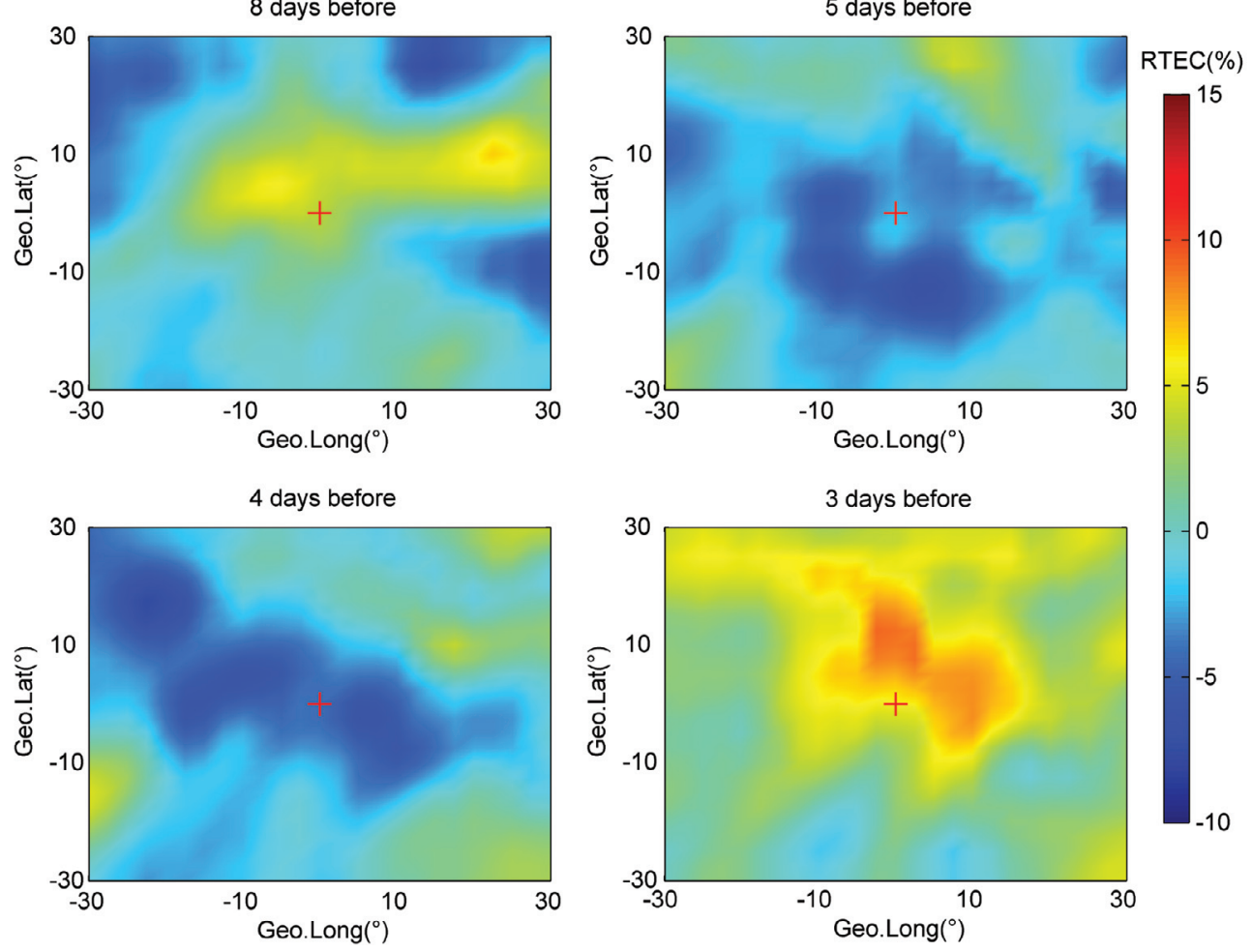

Fig. 5. Two-dimensional maps for relative differential TEC (RTEC) mean during interval 0800 - 1100 UT 3, 4, 5 and 8 days before the earthquakes, respectively. The red pluses mark the epicenters. 
creased again. The variation of the anomalies is $5 \%-10 \%$ about the average. It is noted that the anomalies were localized and mainly distributed in the area with the extent of $30^{\circ}$ in latitude and $30^{\circ}$ in longitude for the epicenters. However, the maximum anomalies did not coincide with the epicenters.

\section{DISCUSSION AND CONCLUSION}

We studied the ionospheric anomalies associated with 20 earthquakes occurred in Qinghai-Tibet region by examining the GPS-inferred TEC variations. In order to detect the seismo-ionospheric perturbations, we used the 15-day running median and the associated standard deviation to construct the upper and lower bounds to isolate the anomalies. We found that the TEC enhancements mainly happened 1 3 days and 8 - 11 days prior to the earthquakes, and usually the TEC decreased $4-7$ days prior to the earthquakes. The earthquakes with exceptional pre-earthquake decrements and enhancements in the GPS-inferred TEC take 65\% and $85 \%$ of the earthquakes we investigated. Moreover, our analysis indicated that the anomalies were not so relevant to the magnitude of the forthcoming earthquakes $(M>5.0)$. In contrast, the focal depth of the earthquakes would govern the occurrence of the upper/lower anomalies. Our result suggests that the different processes of the seismic forcing between the lithosphere, atmosphere and ionosphere may lead to different anomalies over the epicentral areas (Pulinets and Boyarchuk 2004). These anomalies concentrated in the area of $30^{\circ}$ in latitude and $30^{\circ}$ in longitude covering the epicenters and the maximum don't coincide with the epicenters (Pulinets 1998; Yu et al. 2009). The spatial patterns of these anomalies seem to differ from those of the perturbations induced by solar and geomagnetic activities, which usually were registered on a larger and even global scale (Xia et al. 2011).

Many scientists carried out studies of ionospheric anomalies before earthquakes with the help of statistical analysis on typical seismic events (Liu et al. 2001; Pulinets et al. 2003; Liu et al. 2009). Some work about using a stochastic test on statistical analysis of the GPS TEC temporal and spatial variations was done and the reliability of the seismic-ionospheric anomalies was enhanced (Huang 2006; Liu et al. 2010). These studies showed that the impact of the earthquakes mostly of $\mathrm{M}>6.0$, on the ionosphere had some instances of unusual large increase and decrease in ionospheric TEC variations. Some results suggest that these GPS TEC anomalies may be a precursor of large earthquakes.

There are two major potential mechanisms which contribute to the seismogenic ionospheric perturbations. One is that the anomalous vertical electric field near the Earth's surface above the seismogenic zone will penetrate into the ionosphere, causing the irregularities of electron density by the ion drifting (Kelley 1989; Fujinawa and Takahashi
1990; Pulinets et al. 2000). The other is that the atmospheric gravity waves (AGW) forced by earthquakes may propagate upward to perturb into the ionosphere (Weaver et al. 1970; Hayakawa 1999; Liu et al. 2008a). In comparing the features of TEC abnormalities to other ionospheric parameters variations such as foF2 (frequency of F2 layer), Liu et al. (2004) proposed that these anomalies initialized near the Earth's surface, then extended upward to a higher altitude. The anomalous reductions of electron densities may be attributed to the seismo-electromagnetic signals that topically affect the ionospheric plasma (Liu et al. 2009). The anomalous increases, especially the enhanced equatorial ionization anomaly may be associated with the planetary atmospheric waves (Sastri 1998; Zhao et al. 2008a) or related to a downward electric field at the surface (Liu et al. 2009). Liu et al. (2009) also showed that the eastward plasma $E \times B$ drift may cause the abnormal enhancement of TEC slightly shifting to the east of the epicenter as shown in Fig. 5. Although many scientists suggested the possible pre-seismic ionospheric anomalies and tried to understand the nature, pattern of these physical processes, the coupling mechanisms between the lithosphere, atmosphere and ionosphere including the upper ionosphere and the lower magnetosphere remain little known. Attempts to further explore should be carried out for the seismic forcing of the atmosphere and ionosphere. The relationship between earthquakes and ionospheric perturbations which had been demonstrated in our work should be repeatedly testified in the future seismic cases study.

Acknowledgements The work is supported by National Natural Science Foundation of China (Grant No. 40974011, 41004067 and 40804039). The authors appreciate the Crustal Movement Observation Network of China, China Meteorological Administration and IGS for providing GPS data. The solar and geomagnetic indices are available from the NGDC database. The earthquake information is from the United States Geological Survey catalogue (http://earthquake.usgs.gov/earthquakes) and the China Earthquake Administration catalogue (http://www.csndmc.ac.cn/newweb/data.htm). The work benefits from discussion with Wang Qi.

\section{REFERENCES}

Chuo, Y. J., J. Y. Liu, S. A. Pulinets, and Y. I. Chen, 2002: The ionospheric perturbations prior to the Chi-Chi and Chia-Yi earthquakes. J. Geodyn., 33, 509-517, doi: 10.1016/S0264-3707(02)00011-X. [Link]

Dobrovolsky, I. P., S. I. Zubkov, and V. I. Miachkin, 1979: Estimation of the size of earthquake preparation zones. Pure Appl. Geophys., 117, 1025-1044, doi: 10.1007/ BF00876083. [Link]

Fujinawa, Y. and K. Takahashi, 1990: Emission of electromagnetic radiation preceding the Ito seismic swarm of 
1989. Nature, 347, 376-378, doi: 10.1038/347376a0. [Link]

Hayakawa, M., 1999: Atmospheric and Ionospheric Electromagnetic Phenomena Associated with Earthquakes, Terra Sci. Pub. Co., Tokyo.

Hayakawa, M. and Y. Fujinawa, 1994: Electromagnetic Phenomena Relater to Earthquake Predication, Terra Sci. Pub. Co., Tokyo.

Huang, Q., 2006: Search for reliable precursors: A case study of the seismic quiescence of the 2000 western Tottori prefecture earthquake. J. Geophys. Res., 111, B04301, doi: 10.1029/2005JB003982. [Link]

Kelley, M. C., 1989: The Earth's Ionosphere, Elsevier Press, $487 \mathrm{pp}$.

Klobuchar, J. A., 1991: Ionospheric effects on GPS. GPS World, April issue, 48-51.

Leonard, R. S. and R. A. Barnes Jr., 1965: Observation of ionospheric disturbances following the Alaska earthquake. J. Geophys. Res., 70, 1250-1253, doi: 10.1029/ JZ070i005p01250. [Link]

Liperovskaya, E. V., V. A. Liperovsky, A. S. Silina, and M. Parrot, 2006: On spread-F in the ionosphere before earthquakes. J. Atmos. Sol.-Terr. Phys., 68, 125-133, doi: 10.1016/j.jastp.2005.10.005. [Link]

Liu, J. Y., Y. I. Chen, S. A. Pulinets, Y. B. Tsai, and Y. J. Chuo, 2000: Seismo-ionospheric signatures prior to $\mathrm{M} \geq 6.0$ Taiwan earthquakes. Geophys. Res. Lett., 27, 3113-3116, doi: 10.1029/2000GL011395. [Link]

Liu, J. Y., Y. I. Chen, Y. J. Chuo, and H. F. Tsai, 2001: Variations of ionospheric total electron content during the Chi-Chi earthquake. Geophys. Res. Lett., 28, 13831386, doi: 10.1029/2000GL012511. [Link]

Liu, J. Y., Y. J. Chuo, S. J. Shan, Y. B. Tsai, Y. I. Chen, S. A. Pulinets, and S. B. Yu, 2004: Pre-earthquake ionospheric anomalies registered by continuous GPS TEC measurements. Ann. Geophys., 22, 1585-1593, doi: 10.5194/angeo-22-1585-2004. [Link]

Liu, J. Y., Y. B. Tsai, S. W. Chen, C. P. Lee, Y. C. Chen, H. Y. Yen, W. Y. Chang, and C. Liu, 2006: Giant ionospheric disturbances excited by the M9.3 Sumatra earthquake of 26 December 2004. Geophys. Res. Lett., 33, L02103, doi: 10.1029/2005GL023963. [Link]

Liu, J. Y., S. W. Chen, Y. C. Chen, H. Y. Yen, C. P. Chang, W. Y. Chang, L. C. Tsai, C. H. Chen, and W. H. Yang, 2008a: Seismo-ionospheric precursors of the 26 December 2006 M 7.0 Pingtung earthquake doublet. Terr. Atmos. Ocean. Sci., 19, 751-759, doi: 10.3319/ TAO.2008.19.6.751(PT). [Link]

Liu, J. Y., Y. I. Chen, C. H. Chen, C. Y. Liu, C. Y. Chen, M. Nishihashi, J. Z. Li, Y. Q. Xia, K. I. Oyama, K. Hattori, and C. H. Lin, 2009: Seismoionospheric GPS total electron content anomalies observed before the 12 May $2008 M_{w}$ 7.9 Wenchuan earthquake. J. Geophys. Res., 114, A04320, doi: 10.1029/2008JA013698. [Link]
Liu, J. Y., Y. I. Chen, C. H. Chen, and K. Hattori, 2010: Temporal and spatial precursors in the ionospheric global positioning system (GPS) total electron content observed before the 26 December 2004 M9.3 SumatraAndaman Earthquake. J. Geophys. Res., 115, A09312, doi: 10.1029/2010JA015313. [Link]

Liu, L., W. Wan, M. L. Zhang, B. Zhao, and B. Ning, 2008b: Prestorm enhancements in $\mathrm{Nm} F_{2}$ and total electron content at low latitudes. J. Geophys. Res., 113, A02311, doi: 10.1029/2007JA012832. [Link]

Molchanov, O. A. and M. Hayakawa, 1998: Subionospheric VLF signal perturbations possibly related to earthquakes. J. Geophys. Res., 103, 17489-17504, doi: 10.1029/98JA00999. [Link]

Popov, K. V., V. A. Liperovsky, C.-V. Meister, P. F. Biagi, E. V. Liperovskaya, and A. S. Silina, 2004: On ionospheric precursors of earthquakes in scales of 2-3 h. Phys. Chem. Earth, 29, 529-535, doi: 10.1016/j.pce.20 03.10.004. [Link]

Pulinets, S. A., 1998: Strong earthquake prediction possibility with the help of topside sounding from satellites. Adv. Space Res., 21, 455-458, doi: 10.1016/S02731177(97)00880-6. [Link]

Pulinets, S. A. and K. A. Boyarchuk, 2004: Ionospheric Precursors of Earthquakes, Springer, Berlin.

Pulinets, S. A., K. A. Boyarchuk, V. V. Hegai, V. P. Kim, and A. M. Lomonosov, 2000: Quasielectrostatic model of atmosphere-thermosphere-ionosphere coupling. Adv. Space Res., 26, 1209-1218, doi: 10.1016/S02731177(99)01223-5. [Link]

Pulinets, S. A., A. D. Legen'Ka, T. V. Gaivoronskaya, and V. Kh. Depuev, 2003: Main phenomenological features of ionospheric precursors of strong earthquakes. $J$. Atmos. Sol.-Terr. Phys., 65, 1337-1347, doi: 10.1016/j.ja stp.2003.07.011. [Link]

Sastri, J. H., 1998: On the development of abnormally large postsunset upward drift of equatorial $\mathrm{F}$ region under quiet geomagnetic conditions. J. Geophys. Res., 103, 3983-3991, doi: 10.1029/97JA02649. [Link]

Weaver, P. F., P. C. Yuen, G. W. Prolss, and A. S. Furumoto, 1970: Acoustic coupling into the ionosphere from seismic waves of the earthquake at Kurile Islands on August 11, 1969. Nature, 226, 1239-1241, doi: 10. 1038/2261239a0. [Link]

Xia, C., Q. Wang, T. Yu, G. Xu, and S. Yang, 2011: Variations of ionospheric total electron content before three strong earthquakes in the Qinghai-Tibet region. $A d v$. Space Res., 47, 506-514, doi: 10.1016/j.asr.2010.09. 006. [Link]

Yu, T., T. Mao, Y. G. Wang, and J. S. Wang, 2009: Study of the ionospheric anomaly before the Wenchuan earthquake. Chin. Sci. Bull., 54, 1080-1086, doi: 10.1007/ s11434-008-0587-8. [Link]

Zhao, B., M. Wang, T. Yu, W. Wan, J. Lei, L. Liu, and 
B. Ning, 2008a: Is an unusual large enhancement of ionospheric electron density linked with the 2008 great Wenchuan earthquake? J. Geophys. Res., 113, A11304, doi: 10.1029/2008JA013613. [Link]

Zhao, B., W. Wan, L. Liu, K. Igarashi, M. Nakamura, L. J.
Paxton, S.-Y. Su, G. Li, and Z. Ren, 2008b: Anomalous enhancement of ionospheric electron content in the Asian-Australian region during a geomagnetically quiet day. J. Geophys. Res., 113, A11302, doi: 10.1029/2007JA012987. [Link] 